\title{
Gas-Liquid Simulation of An Airlift Bubble Column Reactor
}

\section{Blažej ${ }^{\mathrm{a}}$, G. M. Cartland Glover ${ }^{\mathrm{b}}$, S. C. Generalis ${ }^{\mathrm{b}}$ and J. Markoš $^{\mathrm{a}}$}

${ }^{a}$ Slovak Technical University, Department of Chemical and Biochemical Engineering, Faculty of Chemical and Food Technology, Radlinského 9, Bratislava, 81237 Slovak Republic.

markos@cvt.stuba.sk

${ }^{\mathrm{b}}$ Aston University, School of Engineering and Applied Science, Division of Chemical Engineering and Applied Chemistry, Birmingham, B4 7ET U. K.

S.C.Generalis@aston.ac.uk

The simulation of two-phase flow for an experimental airlift reactor (32-litre volume) using commercially available software from Fluent Incorporated is presented here [1]. Data from the simulation is compared with the experimental data obtained by the tracking of a magnetic particle and analysis of the pressure drop to determine the gas hold-up. Comparisons between vertical velocity and gas hold-up were made for a series of experiments where the superficial gas velocity in the riser was adjusted between 0.01 and $0.075 \mathrm{~m} \mathrm{~s}^{-1}$. 
The understanding of the complexity of the fluid dynamics in airlift reactors is very important due to their application in the bioprocess industry. Understanding the influence that the hydrodynamics has on biochemical production rates through transport processes such as interphase oxygen transfer, nutrient mixing and the effects of $\mathrm{pH}$. Also of importance is knowledge of the influence of the biomass on the gas phase through inter-phase interactions and the impact the biomass has on the liquid phase viscosity. The fluid mixture becomes a pseudo-plastic fluid as the culture grows and develops, limiting the effectiveness of the transport processes discussed above. In an effort to enhance the performance of equipment over the past two decades many attempts have been made to develop accurate and workable predictive models of the flow regimes present. But many of these models do not account for the three-dimensional transient turbulent interactions, which increase the complexity of any solution attempted. The work presented here is an initial comparison between simulated data produced using the computational fluid dynamics (CFD) code for two-phase fluid flow developed by FLUENT Inc. and experimental data recorded using the magnetic tracer particle method for a Newtonian liquid in a 32-litre airlift reactor. The simulations presented here follows on from the simulation of a 5:1 bubble column in two and three dimensions [2], [3].

\section{EXPERIMENTAL}

Experimental investigations were performed using a 32-litre concentric draft-tube airlift reactor, with the riser in the draft-tube and the downcomer between the draft tube and outer cylinder. The dimensions of the column are $1.818 \mathrm{~m}$ of liquid height, with a $0.147 \mathrm{~m}$ column internal diameter. The gas sparger at the base of the column had a diameter of 0.079 m containing 25 holes that were $0.5 \mathrm{~mm}$ in diameter. The draft tube was positioned $0.046 \mathrm{~m}$ above the gas sparger with a tube height was $1.710 \mathrm{~m}$ with an internal diameter of $0.106 \mathrm{~m}$ 
and an external diameter of $0.118 \mathrm{~m}$ (i.e. $6 \mathrm{~mm}$ wall thickness). The cross-sectional area ratio between the downcomer and the riser was 0.95 , with the liquid height to column diameter ratio at 12:1. The top section is a gas disengager with a diameter of $0.294 \mathrm{~m}$. A series of experiments were performed by varying the superficial gas velocity (with respect to the crosssectional area of the riser) over the range of 0.005 to $0.075 \mathrm{~m} \mathrm{~s}^{-1}$ to create a characteristic velocity curve of the airlift reactor. The gas hold-up in the riser and the downcomers was measured using the inverted U-tube Manometer method as described by Chisti [4]. The fluid velocity in the riser and downcomer was measured using a magnetic particle tracing method [5], recording the direction and the time of the particle as it passes through solenoid coils located at a distance of $0.45 \mathrm{~m}$ and $1.5 \mathrm{~m}$ from the base of the reactor.

\section{SIMULATIONS}

The algebraic slip mixture (ASM) model used for the simulations was developed by Manninien et al. [6] and incorporated in Fluent computational fluid dynamics software [1], [7], [8]. This model describes the flow regime as a single-phase pseudo-continuous mixture of the gas and liquid phases. This means that a single set of continuity and momentum equations can be used to model the flow phenomena. The momentum equation is modified to include interactions between each phase as a drift or slip velocity effect. This effect depends on the volume fraction of the dispersed and continuous phases, which is control by a volume fraction equation. In addition to the ASM model the Reynolds stress turbulence transport equations are applied to the solution to account for the effects of turbulence vortices that occur between the gas and liquid phases in the airlift reactor. The transport of turbulent energy is difficult to predict with many unknown and immeasurable parameters that influence the transport of energy, stress and vortices in a turbulent flow. Therefore to capture all these 
effects requires the use of a complex model, such as the Reynolds stresses turbulence transport model. The model originates from the exact Reynolds stress turbulence transport equation. The exact equation has many unknown terms and is employed in a series of equations to enable closure of each of the unknown terms in the exact equation. This includes the use of both the k- $\varepsilon$ equations and the inclusion of other effects such as buoyancy, pressure, pressure-strain and any rotation. The transport equations described here take account of the turbulent interactions between the two fluids in the airlift reactor and are found in the appendix, where quations 1 to 9 are used to model the transport of the gas-liquid mixture and equations 10 to 24 model the transport of turbulent energy, stresses and vortices.

Figure 1A shows the domain used to represent the 32-litre reactor. This domain contained $\sim 2500$ cells in an unstructured format to reduce the number of mesh cells used where figure $1 \mathrm{~B}$ and $1 \mathrm{C}$ show the configuration of the mesh at the top and bottom of the domain. The mesh from the bottom section extends up the column to the top section, with an even distribution of cells. The flow boundary conditions applied to the mixture phase set the vertical gas velocity as $0.018,0.036,0.072,0.090,0.108$ and $0.135 \mathrm{~m} \mathrm{~s}^{-1}$, with respect to the cross-sectional area of the sparger, the gravitational acceleration as $9.81 \mathrm{~m} \mathrm{~s}^{-2}$, and the bubble diameter as $5 \mathrm{~mm}$. Table 1 display the corresponding superficial gas velocities for the experimental data, this superficial velocity is obtain with respect to the riser cross-sectional area.

The solver specifications for the discretization of the domain involve the following procedures, "body force weighted" for pressure [8], QUICK [9] for momentum, SIMPLEC 
[10] for the velocity-pressure coupling and a first-order discretization scheme for the volume fraction and unsteady state, turbulent flow models. The under-relaxation factors, which determine how much control each of the equations has in the final solution, were set to 0.3 for the pressure, 0.7 for the momentum with the Reynolds stress turbulence transport model, slip velocity, volume fraction equations being set at 0.1 . The under relaxation factors for the $\mathrm{k}-\varepsilon$ turbulence transport model, density and body forces were set to 1 .

The simulations were performed for 2000 time-steps with a step size of 0.1 seconds; to give 200 seconds of simulated flow time. After every time-step the vertical velocity of the liquid phase was recorded as an average of 16 points across the width of the riser and 16 points across the width of each downcomer at heights 0.45 from the base of the reactor. The gas phase holdup was recorded after each time step as an average with respect to the whole of the riser section of the column and for both of the downcomer sections.

\section{RESULTS AND DISCUSSION}

Figure 2 to Figure 5 present the vertical liquid phase velocity and the gas phase holdup for both the experimental and simulated results. Each of the simulated data curves is averaged with respect to space and then time. At each time-step an average value of the liquid velocity was recorded, this was a spatial average that comprised of the mean velocity of sixteen data points for the riser and 16 points for each downcomer at a height of $0.45 \mathrm{~m}$ above the gas sparger. The gas phase holdup was obtained by averaging the all values in the riser

and for the downcomer. These spatial averages were then averaged with respect to time, 
between 5 and 200 seconds of simulation time. For the experimental data a magnetically permeable particle was placed in the airlift reactor. As the particle travelled about the column with the liquid phase motion and as it passed through solenoid coils measuring an electrical signal, a change in this signal was observed. This change in signal appears as peaks, and the time difference in the peaks can be used to calculate the velocity of the gas-liquid mixture in both the riser and the downcomer. The series of peaks were used to produce a time-averaged velocity, but as a particle rather than a point location was used the velocity is also averaged with respect to space. The gas holdup was determined by measuring the pressure difference across each section of the column (i.e. the riser and the downcomer) with manometers.

Figure 2 presents the vertical velocity in the riser for the experimental (匹) and simulated data $(\triangle)$ against the superficial gas velocity in the riser. The trend of the experimental data is that of rapidly rising velocity up to $2 \mathrm{~cm} \mathrm{~s}^{-1}$ of the $\mathrm{U}_{\mathrm{GRC}}$. Then there is a reduction in the rate of change of the velocity as the turbulent flow effects begin to influence the gas phase motion for $\mathrm{U}_{\mathrm{GRC}}$ greater than $2 \mathrm{~cm} \mathrm{~s}^{-1}$. This change in the velocity profile is also observed in the simulated data at $2 \mathrm{~cm} \mathrm{~s}^{-1}$ but more data points are required below this value is required to confirm the change. But generally the profile of the simulated data fits the empirical profile, except for the highest superficial gas velocity where a difference of greater than $15 \%$ or $10 \mathrm{~cm} \mathrm{~s}^{-1}$ occurs.

The gas holdup in the riser is displayed in Figure 3 where comparisons of experimental ( $\square)$ and simulated data $(\triangle)$ are made. The experimental gas holdup profile is linear with respect to the superficial gas velocity in the riser, suggesting that the slip of 
relative velocity between the gas and liquid phases does not change with increased gas through put. The gas fraction obtained from the simulated data over-predicts the empirical data, though the profile also has a linear form. The accuracy of the result is greater for the lower superficial gas velocities than at the high gas velocities.

The next figure presents the liquid phase velocity in the downcomer (Figure 4) and again the empirical data display two rates of change of velocity above and below $2 \mathrm{~cm} \mathrm{~s}^{-1}$. The flow regime changes as the influence of turbulent flow effects increase. The simulated data consistently over-predicts the liquid velocity and though the profile is not linear, more data is required for the lower range of superficial gas velocities is required to confirm this effect. The profiles in Figure 5 confirm this reduction in the accuracy of the flow data between the riser and downcomer where the gas holdup profiles are presented. Where a near linear change in the holdup is observed with the experimental data, the simulated data show comparatively little increase in the holdup of the downcomer for the majority of the superficial gas velocities. The only significant increases in the holdup in the downcomers occur at superficial gas velocities greater than $5 \mathrm{~cm} \mathrm{~s}^{-1}$. There are three effects in the model used that could influence the accuracy of the simulation in the downcomer, the use of a single gas fraction of a mean bubble size, the volume fraction equation formulation and the resolution of the mesh in the downcomer.

Figures 6-8 present the vector plots of the mixture phase from the numerical experiments. For this particular case the superficial gas velocity in the riser was $2 \mathrm{~cm} \mathrm{~s}^{-1}$ and represent the state of the vector field after 200 seconds of simulation time. The dark shade vectors represent 
areas of low velocity for the fluid mixture. The highest numerically observed velocities were of the order of $0.9 \mathrm{~m} \mathrm{~s}^{-1}$ at the peaks of the meandering motion across the length riser. The oscillatory states were also visually observed experimentally.

For simplicity of the model and the exclusion of effects such as coalescence and bubble break-up, a single bubble size was used whereas a bi-modal bubble distribution occurs for high superficial gas velocities [11-14]. This effect can be observed in through the holdup in the downcomer and where very low superficial velocities lead to negligible gas holdup (less than $1 \mathrm{~cm} \mathrm{~s}^{-1}$ ) as the driving forces increase the holdup increases as smaller bubbles are entrained in the downcomer flow. As smaller (less than $2 \mathrm{~mm}$ ) are not modelled this effect is not observed in the simulation, but as the forces causing entrainment of the bubbles increase with increasing superficial gas velocity, the larger bubble become entrained. This is described by the small increases in the gas hold-up at superficial gas velocities greater than $0.05 \mathrm{~cm} \mathrm{~s}^{-1}$. Also the volume fraction equation used to model could influence how well the entrainment of gas bubbles in the downcomer fluids is modelled. The volume fraction equation is essentially a scalar equation modelling the transport of the gas phase fraction, looking at equation 3 , there are three terms modelled. These are the change of fraction with respect to time, the convective transport of the gas phase and the inter-phase interaction term. This equation does not include terms such as diffusion and the deviatoric stress tensor that could incorporate entrainment of the gas phase bubbles into the downcomer fluids and therefore is not capturing an important part of the characterisation of airlift reactors. Finally the resolution of the mesh in the downcomer and at the regions where the fluid enters and leaves could also determine how well the gas phase entrainment is modelled here. 


\section{CONCLUSIONS}

Gas phase holdup and liquid phase velocities in the riser are modelled to high accuracy, but the downcomer flow characterisation is poor due effects caused by the choice of the bubble size, volume fraction equation and mesh resolution used. Therefore to accurately model the motion of gas and liquid phases in airlift reactors, the use of complex multiple gas/discrete phase model equations must be implemented, where each discrete phase represents a single bubble size for the same gas phase composition. The inclusion of more than one gas phase will also lead to requirement of modelling bubble coalescence and break-up as this occurs in airlift reactors and this should be accompanied by a study of the bubble population in such reactors. Further investigations into the volume fraction equation used to model the gas phase transport are also required to assess how well the model equation captures bubble entrainment into the downcomer flows. It is also recommended that higher resolutions of the mesh in the region where there are large gradients in the velocity and the volume fraction of the gas phase, as this could inhibit gas phase transport.

Acknowledgements. We would like to acknowledge the support of Inco-Copernicus Grant number ERB IC15-CT98-0904 and Fluent Incorporated for enabling this work to be presented. 


\section{APPENDIX}

\section{Table}

Table 1: Superficial gas phase velocity $\left(\mathrm{m} \mathrm{s}^{-1}\right)$ through the riser and through the sparger to enable comparisons between simulation and experiment. The sparger velocity is used defined the gas phase velocity in the simulations. Note that the gas flow rate corresponds to both the riser and sparger superficial gas velocities.

\begin{tabular}{|c|c|c|}
\hline Column section & Riser & Sparger \\
\hline Cross-sectional area $* 10^{-3}\left(\mathrm{~m}^{2}\right)$ & 8.82 & 4.90 \\
\hline Gas flow rate $* 10^{-4}\left(\mathrm{~m} \mathrm{~s}^{-3}\right)$ & Superficial gas velocity $\left(\mathrm{m} \mathrm{s}^{-1}\right)$ & Superficial gas velocity $\left(\mathrm{m} \mathrm{s}^{-1}\right)$ \\
\hline 0.88 & 0.01 & 0.018 \\
\hline 1.76 & 0.02 & 0.036 \\
\hline 3.53 & 0.04 & 0.072 \\
\hline 4.41 & 0.05 & 0.090 \\
\hline 5.29 & 0.06 & 0.108 \\
\hline 6.62 & 0.075 & 0.135 \\
\hline
\end{tabular}




\section{Figures}

A:

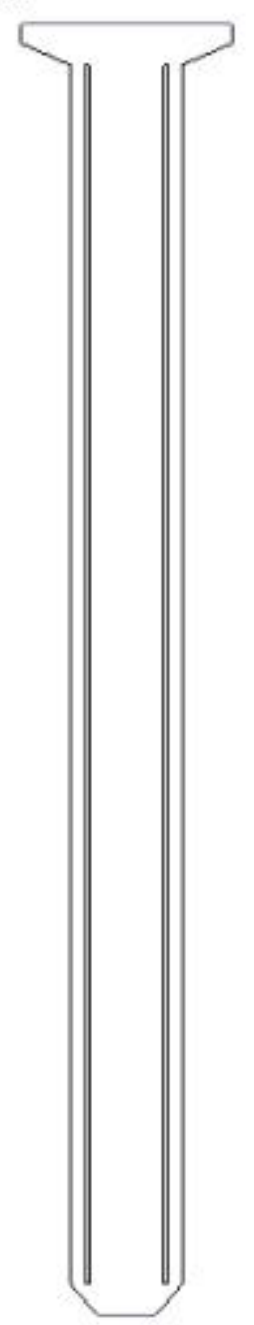

B:

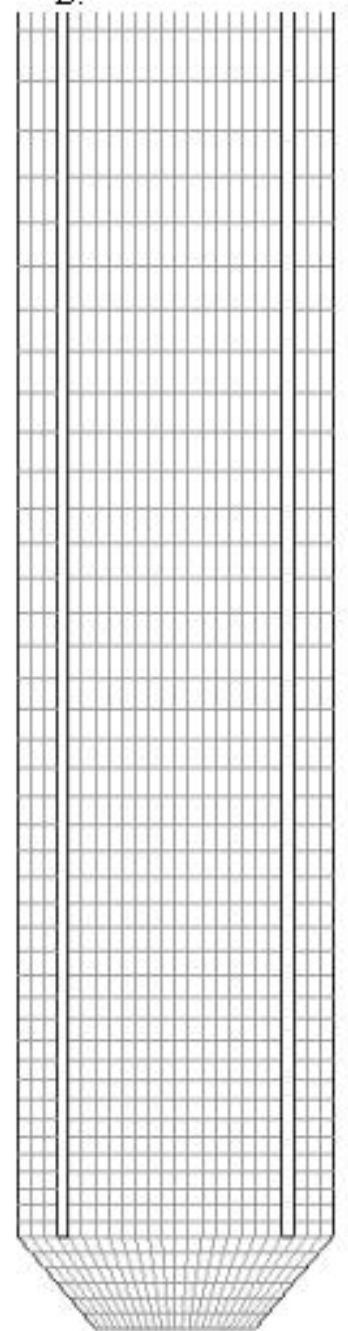

C:

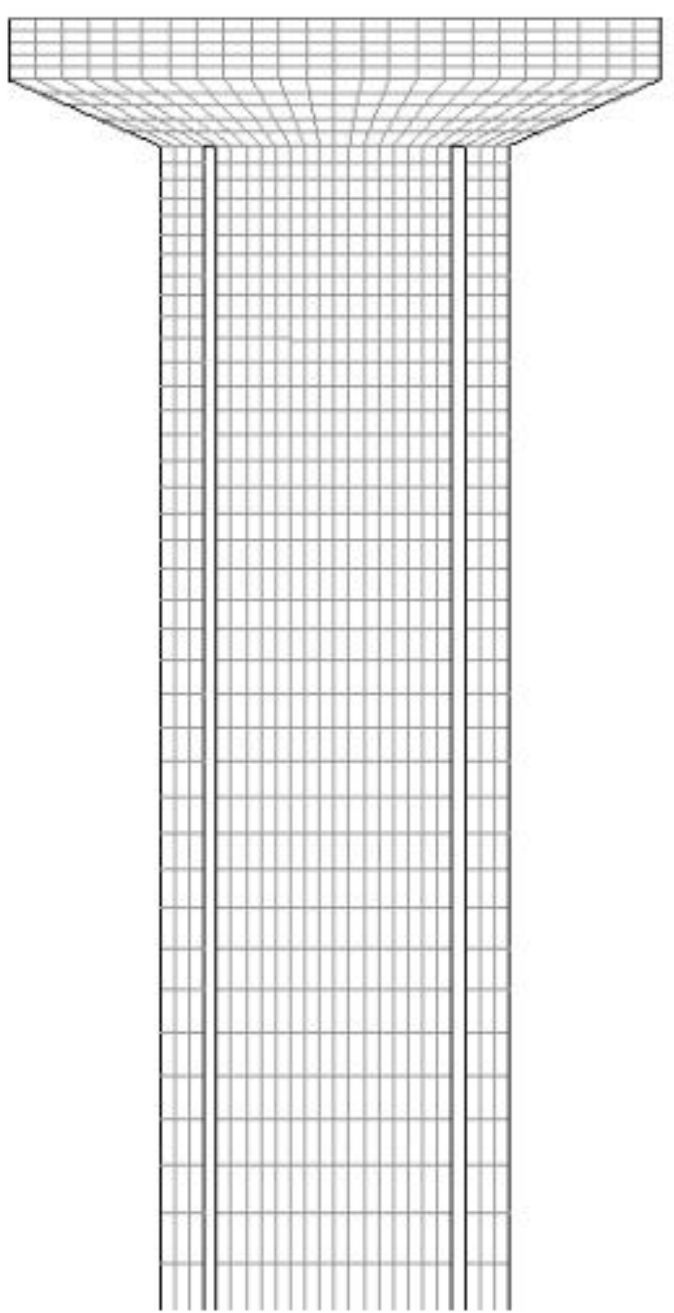

Figure 1: Diagram of the domain used to represent the airlift reactor in the simulation. A: The whole domain; B: The bottom of the reactor; C: The top of the reactor; 


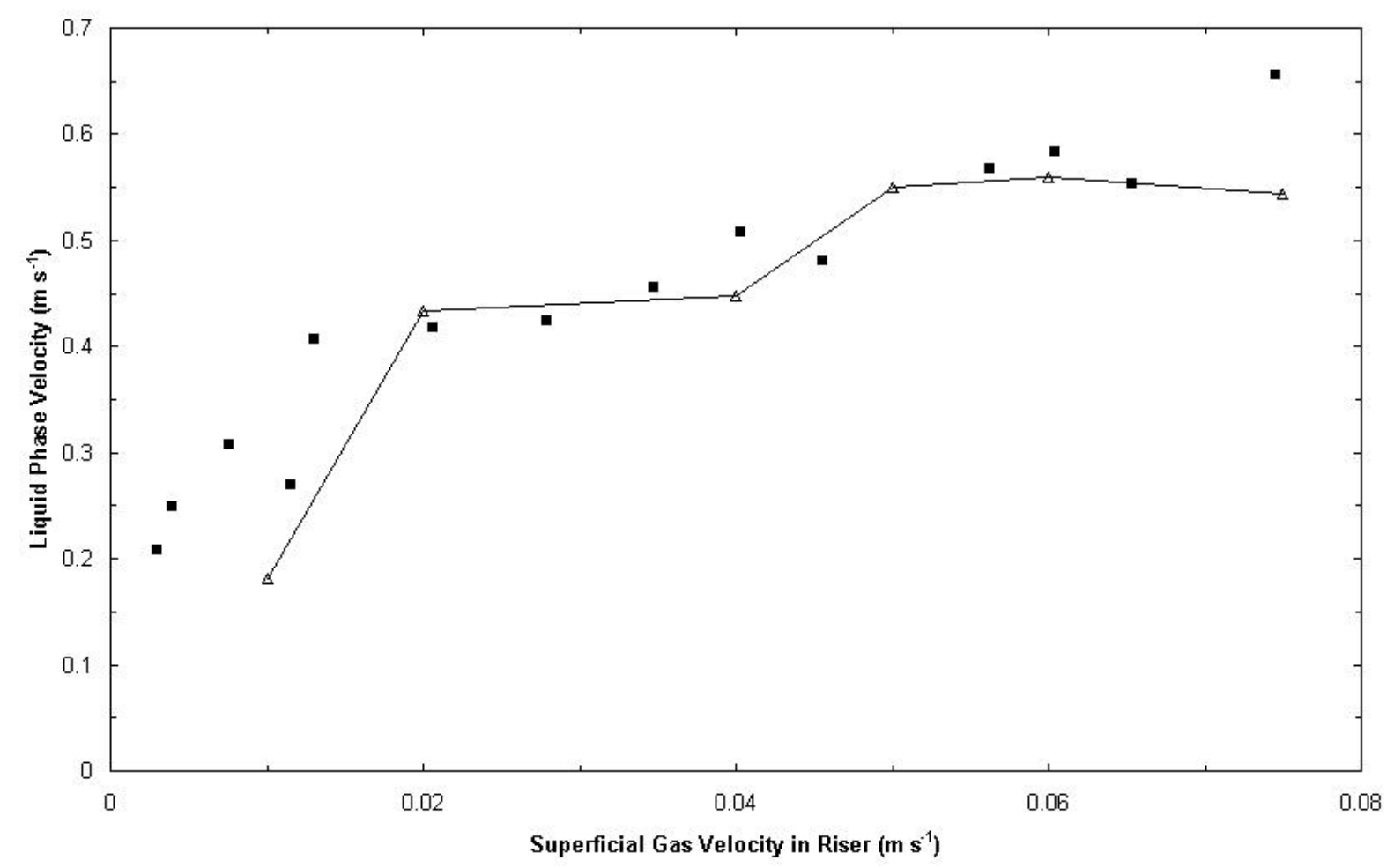

Figure 2: Liquid phase velocity $\left(\mathrm{m} \mathrm{s}^{-1}\right)$ in the riser as influenced by the superficial gas velocity in the riser $\left(\mathrm{m} \mathrm{s}^{-1}\right) ; \mathbf{\square}$ : Experimental data collated from the magnetic particle; $\triangle$ : Simulated data obtained from Fluent [1]; 


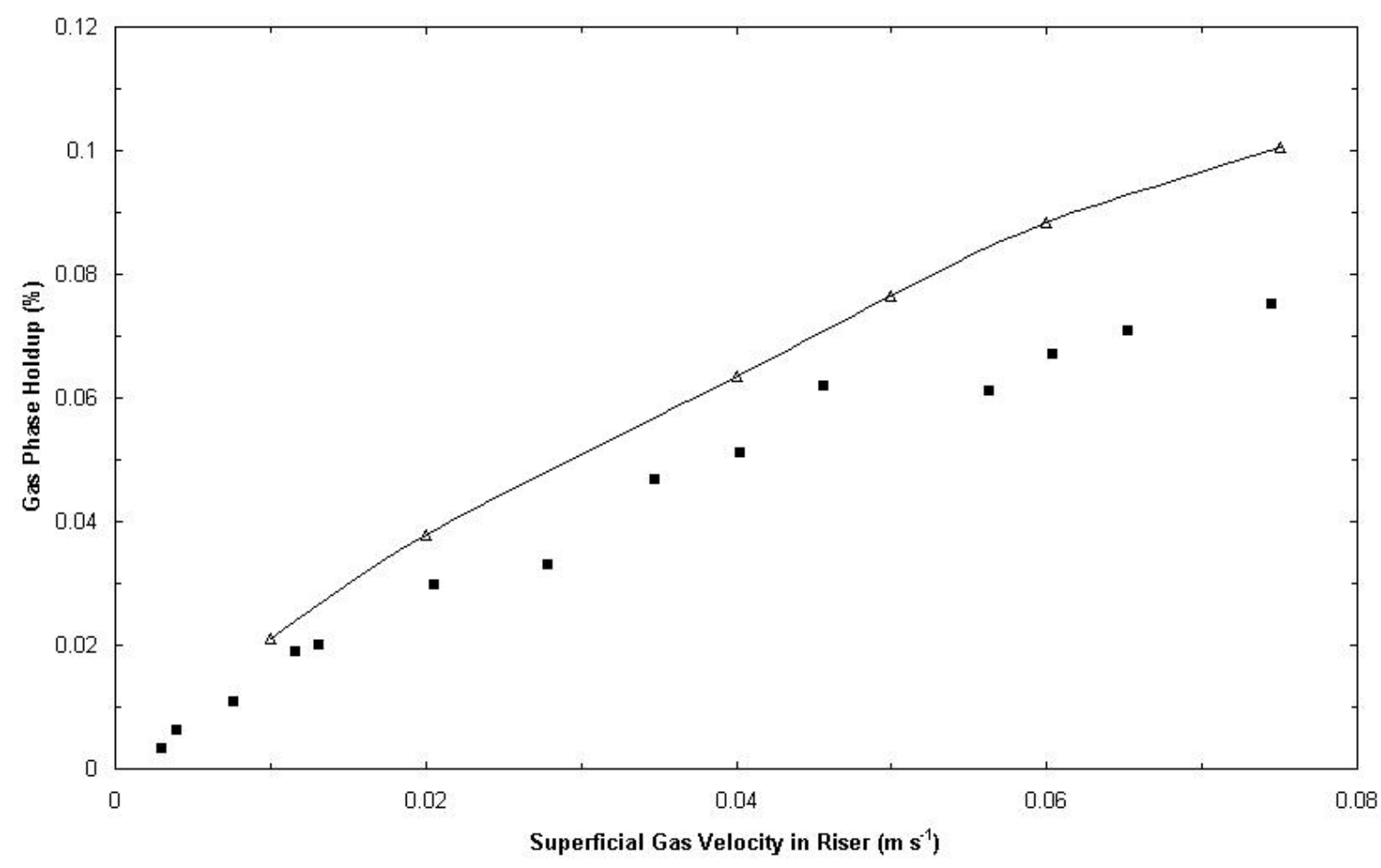

Figure 3: Gas phase holdup (\%) in the riser as influenced by the superficial gas velocity in the riser $\left(\mathrm{m} \mathrm{s}^{-1}\right)$; $:$ Experimental data collated from the magnetic particle; $\triangle$ : Simulated data obtained from Fluent [1]; 


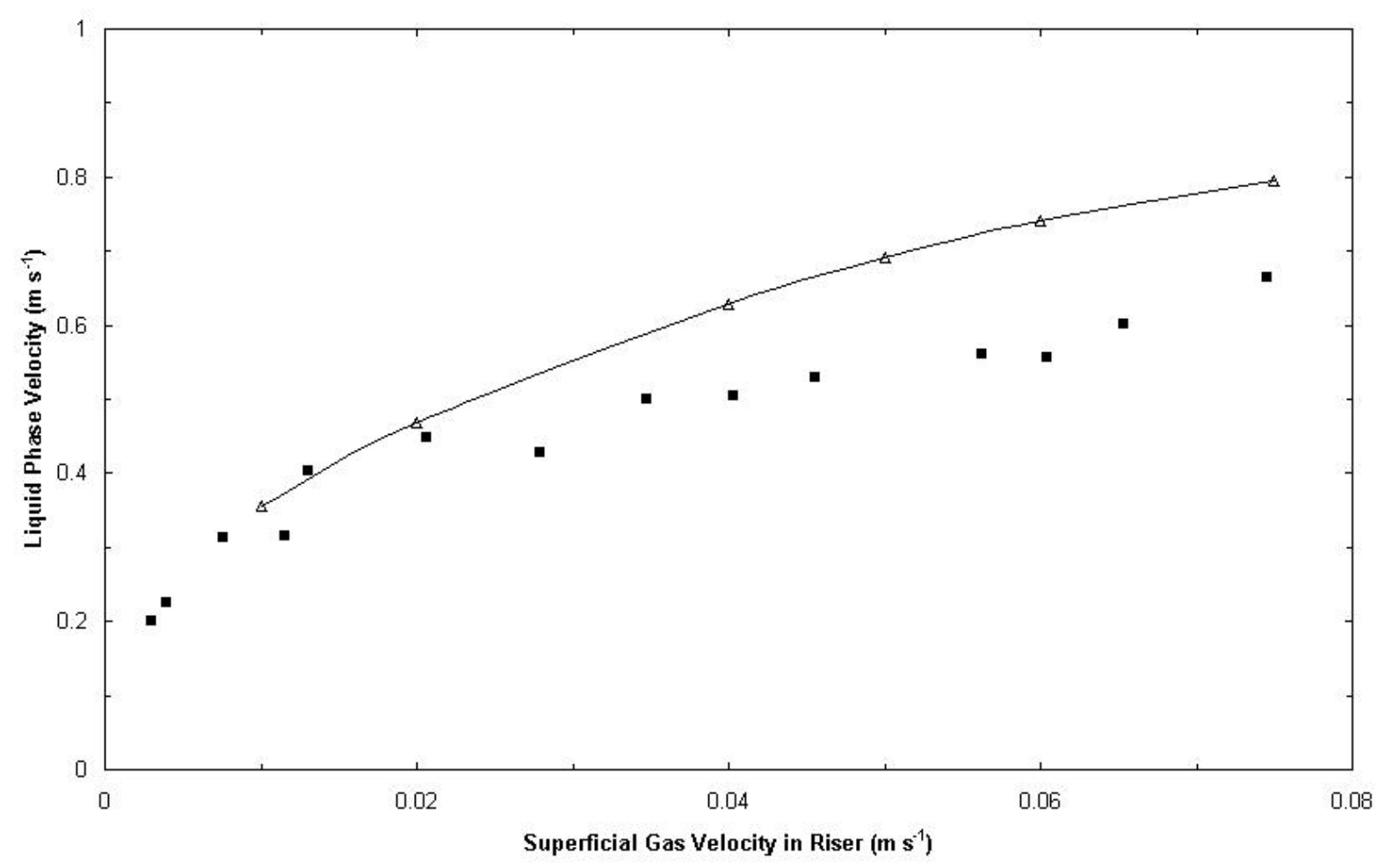

Figure 4: Liquid phase velocity $\left(\mathrm{m} \mathrm{s}^{-1}\right)$ in the downcomer as influenced by the superficial gas velocity in the riser $\left(\mathrm{m} \mathrm{s}^{-1}\right)$; $\mathbf{\square}$ : Experimental data collated from the magnetic particle; $\triangle$ : Simulated data obtained from Fluent [1]; 


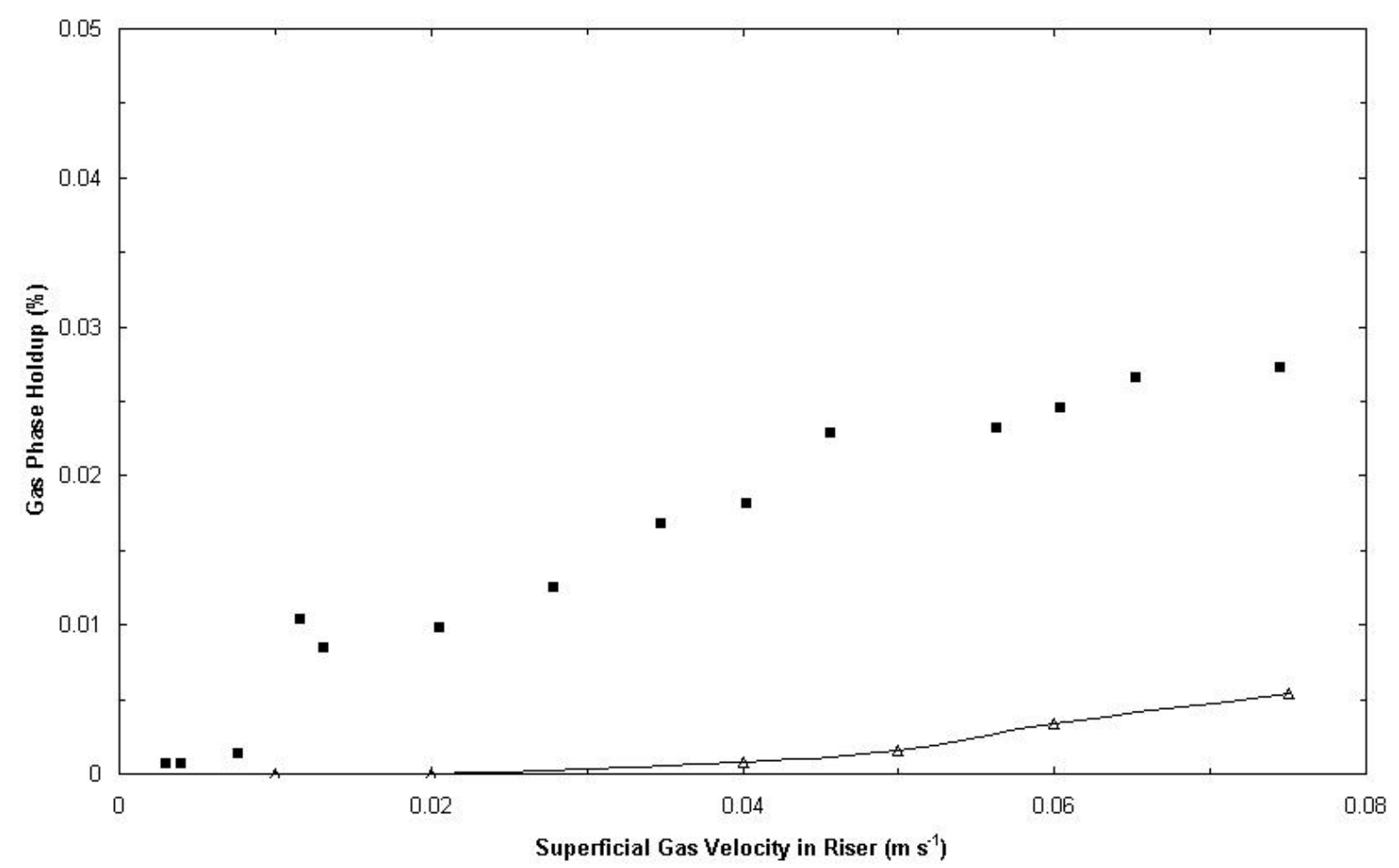

Figure 5: Gas phase holdup (\%) in the downcomer as influenced by the superficial gas velocity in the riser $\left(\mathrm{m} \mathrm{s}^{-1}\right)$; $\mathbf{\square}$ : Experimental data collated from the magnetic particle; $\triangle$ : Simulated data obtained from Fluent [1]; 
A:

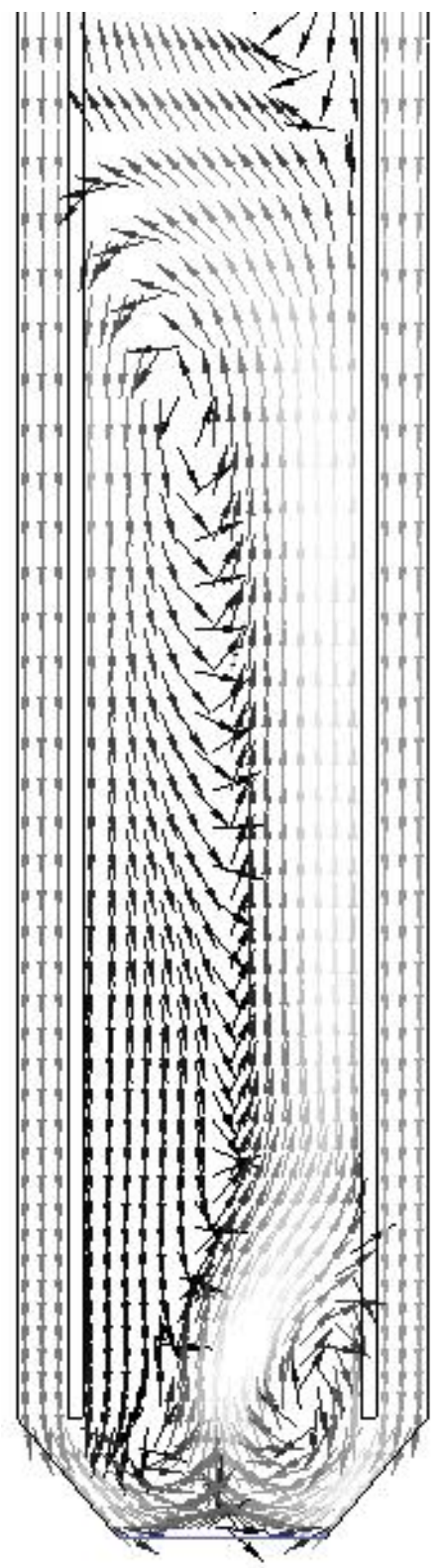

B:

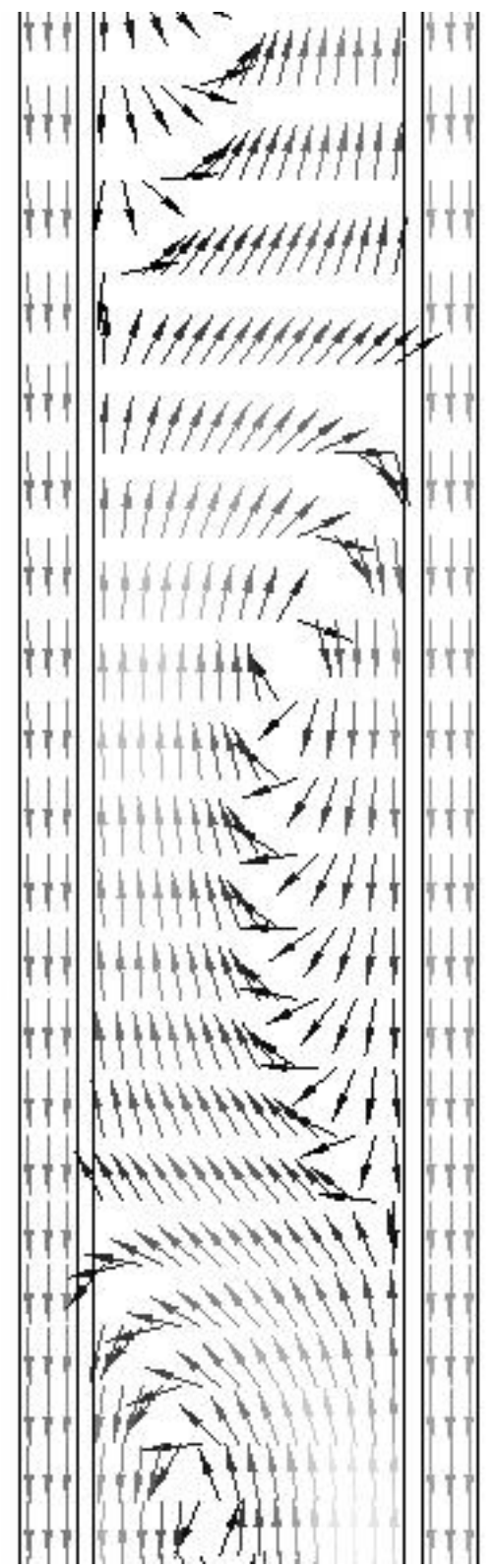

Figure 6: Vectors of velocity magnitude for the mixture phase $\left(\mathrm{m} \mathrm{s}^{-1}\right)$; A: Between 0 and 0.55 $\mathrm{m}$ above the base of the reactor; $\mathrm{B}$ : Between 0.55 and $0.85 \mathrm{~m}$ above the base of the reactor; 
A:

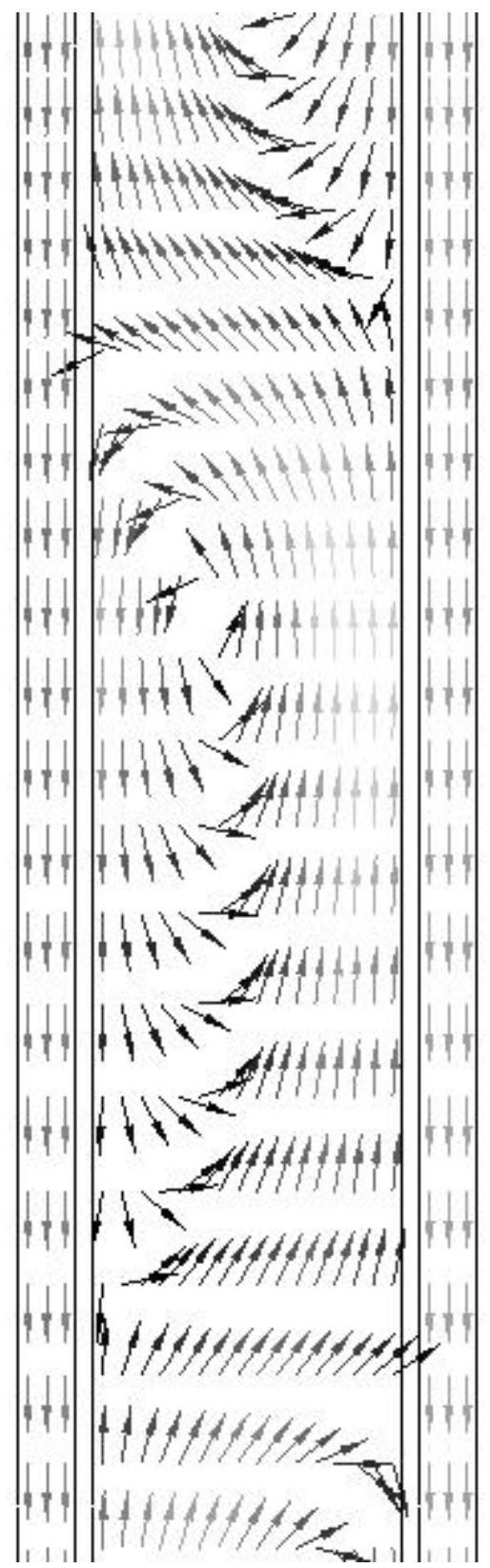

B:

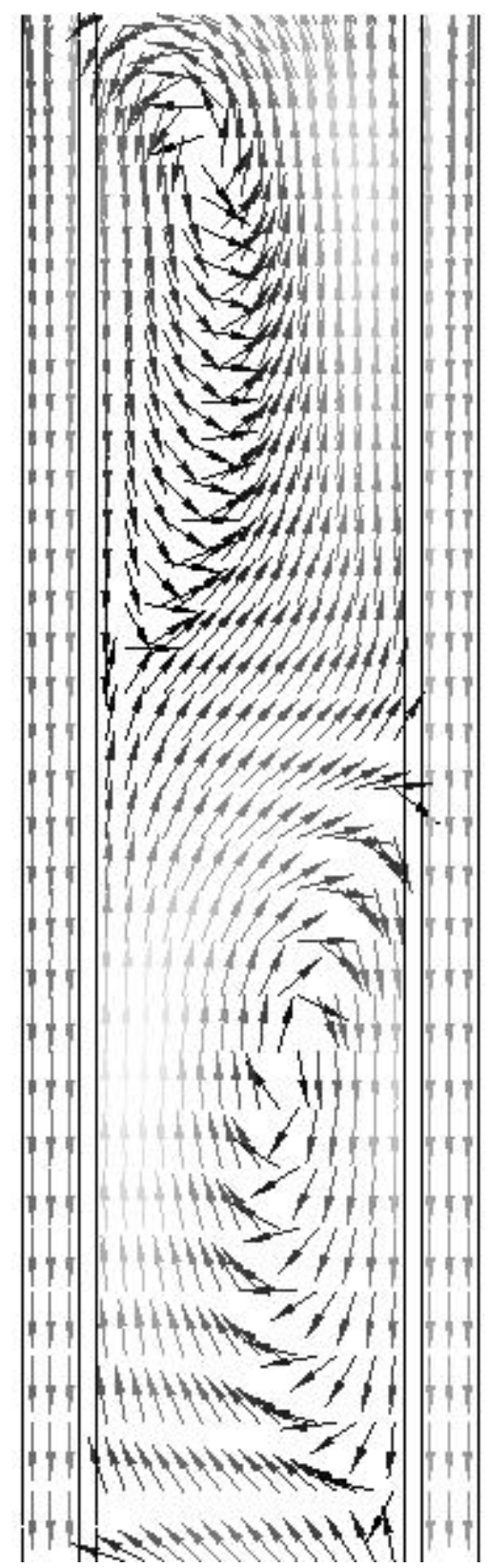

Figure 7: Vectors of velocity magnitude for the mixture phase $\left(\mathrm{m} \mathrm{s}^{-1}\right)$; A: Between 0.85 and $1.25 \mathrm{~m}$ above the base of the reactor; B: Between 1.25 and $1.7 \mathrm{~m}$ above the base of the reactor; 


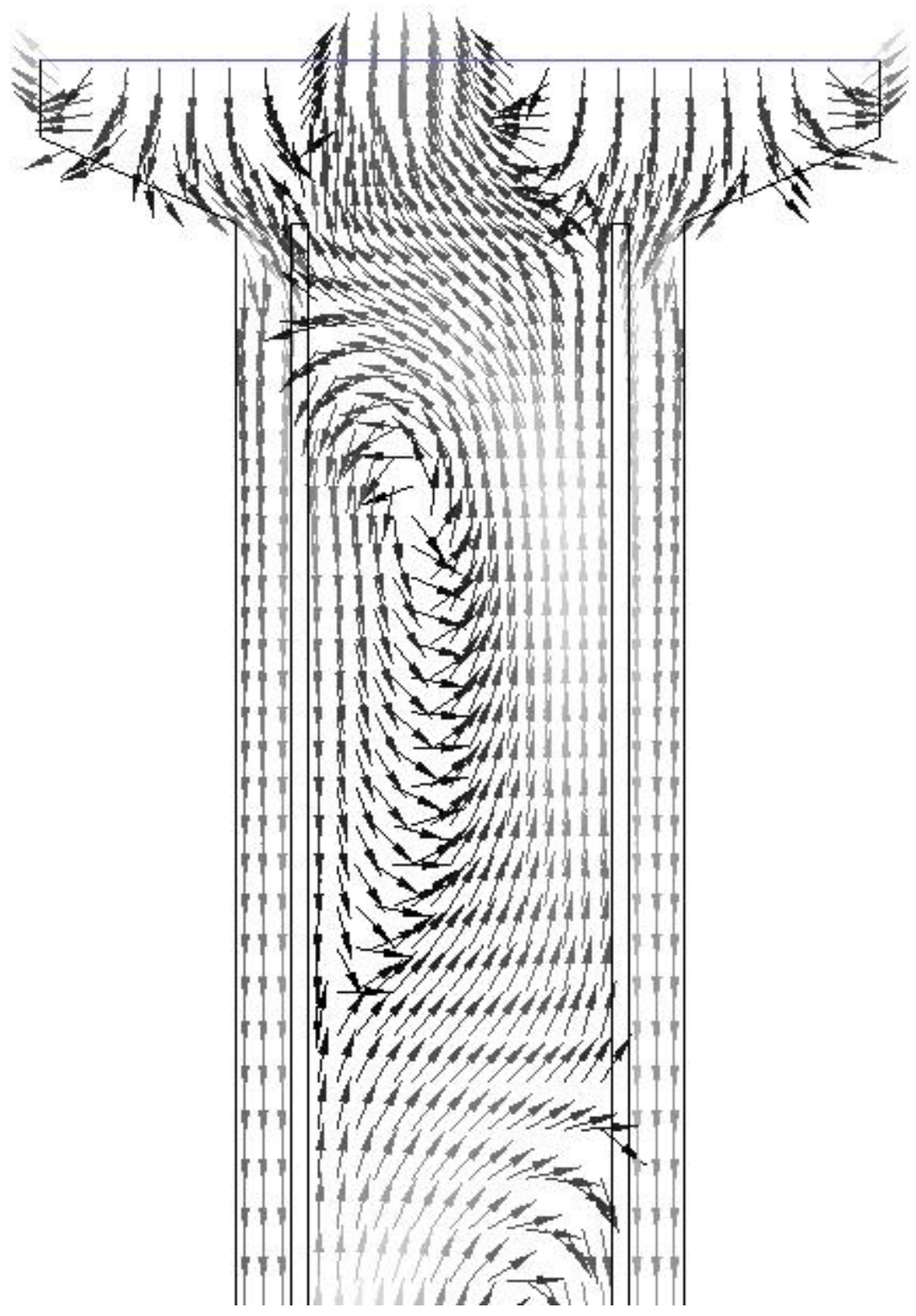

Figure 8: Vectors of velocity magnitude for the mixture phase $\left(\mathrm{m} \mathrm{s}^{-1}\right)$ between 1.45 and 1.818 $\mathrm{m}$ above the base of the reactor; 


\section{Model Equations}

1. continuity equation for the mixture phase

$$
\frac{\partial}{\partial t}\left(\rho_{m}\right)+\frac{\partial}{\partial x_{i}}\left(\rho_{m} u_{m, i}\right)=0
$$

2. momentum equation for the mixture

$$
\begin{aligned}
& \frac{\partial}{\partial t}\left(\rho u_{m, j}\right)+\frac{\partial}{\partial x_{i}}\left(\rho_{m} u_{m, i} u_{m, j}\right)= \\
& -\frac{\partial p}{\partial x_{j}}+\frac{\partial}{\partial x_{j}} \mu_{m}\left(\frac{\partial}{\partial x_{j}}\left(u_{m, i}\right)+\frac{\partial}{\partial x_{i}}\left(u_{m, j}\right)\right) \\
& +\rho_{m} g_{j}+F_{j}+\frac{\partial}{\partial x_{i}} \sum_{k=1}^{n} \alpha_{p} \rho_{p} u_{D p, i} u_{D p, j}
\end{aligned}
$$

3. volume fraction equation

$$
\frac{\partial}{\partial t}\left(\alpha_{p} \rho_{p}\right)+\frac{\partial}{\partial x_{i}}\left(\alpha_{p} \rho_{p} u_{m, i}\right)=-\frac{\partial}{\partial x_{i}}\left(\alpha_{p} \rho_{p} u_{D p, i}\right)
$$

4. mixture density

$$
\rho_{\mathrm{m}}=\sum_{\mathrm{p}=1}^{\mathrm{n}} \alpha_{\mathrm{p}} \rho_{\mathrm{p}}
$$


5. mixture viscosity

$$
\mu_{\mathrm{m}}=\sum_{\mathrm{p}=1}^{\mathrm{n}} \alpha_{\mathrm{p}} \mu_{\mathrm{p}}
$$

6. mass averaged velocity

$$
\overrightarrow{\mathrm{u}}_{\mathrm{m}}=\frac{\sum_{\mathrm{p}=1}^{\mathrm{n}} \alpha_{\mathrm{p}} \rho_{\mathrm{p}} \overrightarrow{\mathrm{u}}_{\mathrm{p}}}{\rho_{\mathrm{m}}}
$$

7. drift velocity

$$
\overrightarrow{\mathrm{u}}_{\mathrm{D}, \mathrm{p}}=\overrightarrow{\mathrm{u}}_{\mathrm{p}}-\overrightarrow{\mathrm{u}}_{\mathrm{m}}=\overrightarrow{\mathrm{V}}_{\mathrm{p}, \mathrm{c}}-\frac{1}{\rho_{\mathrm{m}}} \sum_{\mathrm{i}=1}^{\mathrm{n}-1} \alpha_{\mathrm{p}} \rho_{\mathrm{p}} \overrightarrow{\mathrm{v}}_{\mathrm{i}, \mathrm{c}}
$$

8. slip velocity equation

$$
\overrightarrow{\mathrm{v}}_{\mathrm{p}, \mathrm{c}}=\overrightarrow{\mathrm{u}}_{\mathrm{p}}-\overrightarrow{\mathrm{u}}_{\mathrm{c}}=\frac{\left(\rho_{\mathrm{m}}-\rho_{\mathrm{p}}\right)}{18 \mu_{\mathrm{c}} \mathrm{f}}\left(\mathrm{g}_{\mathrm{j}}-\frac{\wp \overrightarrow{\mathrm{u}}_{\mathrm{m}}}{\mathrm{t}_{\mathrm{t}}}\right)
$$

9. friction factor

$$
\mathrm{f}=0.018 \operatorname{Re} \quad \operatorname{Re} \geq 1000
$$

10. turbulent kinetic energy transport equation

$$
\rho \frac{\mathrm{Dk}}{\mathrm{Dt}}=\frac{\partial}{\partial \mathrm{x}_{\mathrm{i}}}\left[\left(\mu+\frac{\mu_{\mathrm{t}}}{\sigma_{\mathrm{k}}}\right) \frac{\partial \mathrm{k}}{\partial \mathrm{x}_{\mathrm{i}}}\right]+\mathrm{G}_{\mathrm{k}}+\mathrm{G}_{\mathrm{b}}-\rho \varepsilon
$$


11. rate of dissipation of energy from turbulent flow, transport equation

$$
\rho \frac{\mathrm{D} \varepsilon}{\mathrm{Dt}}=\frac{\partial}{\partial \mathrm{x}_{\mathrm{i}}}\left(\mu+\frac{\mu_{\mathrm{t}}}{\sigma_{\varepsilon}}\right) \frac{\partial \varepsilon}{\partial \mathrm{x}_{\mathrm{i}}}+\mathrm{C}_{1 \varepsilon} \frac{\varepsilon}{\mathrm{k}}\left(\mathrm{G}_{\mathrm{k}}+\mathrm{C}_{3 \varepsilon} \mathrm{G}_{\mathrm{b}}\right)-\mathrm{C}_{2 \varepsilon} \frac{\varepsilon^{2}}{\mathrm{k}}
$$

12. turbulent viscosity formulation

$$
\mu_{\mathrm{t}}=\rho \mathrm{C}_{\mu} \frac{\mathrm{k}^{2}}{\varepsilon}
$$

13. total derivative for the turbulent kinetic energy

$$
\frac{\mathrm{Dk}}{\mathrm{Dt}}=\frac{\partial \mathrm{k}}{\partial \mathrm{t}}+\frac{\partial \mathrm{ku}}{\partial \mathrm{x}_{\mathrm{i}}}
$$

14. total derivative for the rate of dissipation of energy from the turbulent flow

$$
\frac{\mathrm{D} \varepsilon}{\mathrm{Dt}}=\frac{\partial \varepsilon}{\partial \mathrm{t}}+\frac{\partial \varepsilon \mathrm{u}}{\partial \mathrm{x}_{\mathrm{i}}}
$$


15. exact transport equation for the transport of Reynolds Stresses

$$
\begin{aligned}
& \frac{\partial}{\partial t}\left(\rho \overline{u_{i} u_{j}}\right)+\frac{\partial}{\partial x_{r}}\left(\rho U_{r} \overline{u_{i} u_{j}}\right)= \\
& -\frac{\partial}{\partial x_{r}}\left[\rho \overline{u_{i} u_{j} u_{r}}+\bar{p}\left(\delta_{r j} u_{i}+\delta_{i r} u_{j}\right)\right] \\
& +\frac{\partial}{\partial x_{r}}\left[\mu \frac{\partial}{\partial x_{r}}\left(\overline{u_{i} u_{j}}\right)\right]-\rho\left(\overline{u_{i} u_{r}} \frac{\partial U_{j}}{\partial x_{r}}+\overline{u_{j} u_{r}} \frac{\partial U_{i}}{\partial x_{r}}\right) \\
& -\rho \beta\left(g_{i} \overline{u_{j} \theta}+g_{j} \overline{u_{i} \theta}\right)+p\left(\frac{\partial u_{i}}{\partial x_{j}}+\frac{\partial u_{j}}{\partial x_{i}}\right) \\
& -2 \mu \overline{\frac{\partial \mathrm{u}_{\mathrm{i}}}{\partial \mathrm{x}_{\mathrm{r}}} \frac{\partial \mathrm{u}_{\mathrm{j}}}{\partial \mathrm{x}_{\mathrm{r}}}}-2 \rho \Omega_{\mathrm{r}}\left(\overline{\mathrm{u}_{\mathrm{j}} \mathrm{u}_{\mathrm{s}} \varepsilon_{\mathrm{iks}}}+\overline{\mathrm{u}_{\mathrm{i}} \mathrm{u}_{\mathrm{s}} \varepsilon_{\mathrm{jks}}}\right)
\end{aligned}
$$

16. turbulent diffusive transport

$$
\frac{\partial}{\partial \mathrm{x}_{\mathrm{r}}}\left[\rho \overline{\mathrm{u}_{\mathrm{i}} \mathrm{u}_{\mathrm{j}} \mathrm{u}_{\mathrm{r}}}+\overline{\mathrm{p}}\left(\overline{\delta_{\mathrm{rj}} \mathrm{u}_{\mathrm{i}}+\delta_{\mathrm{ir}} \mathrm{u}_{\mathrm{j}}}\right)\right]=\frac{\partial}{\partial \mathrm{x}_{\mathrm{r}}}\left(\frac{\mu_{\mathrm{t}}}{\sigma_{\mathrm{k}}} \frac{\partial}{\partial \mathrm{x}_{\mathrm{r}}}\left(\overline{\mathrm{u}_{\mathrm{i}} \mathrm{u}_{\mathrm{j}}}\right)\right)
$$

17. buoyancy effects

$$
B_{i j}=\rho \beta\left(g_{i} \overline{u_{j} \theta}+g_{j} \overline{u_{i} \theta}\right)=\beta \frac{\mu_{t}}{P_{r_{t}}}\left(g_{i} \frac{\partial \rho}{\partial x_{j}}+g_{j} \frac{\partial \rho}{\partial x_{i}}\right)
$$


18. stress production

$$
P_{i j}=\rho\left(\overline{u_{i} u_{r}} \frac{\partial U_{j}}{\partial x_{r}}+\overline{u_{j} u_{r}} \frac{\partial U_{i}}{\partial x_{r}}\right)
$$

19. system rotation effects

$$
\mathrm{F}_{\mathrm{ij}}=2 \rho \Omega_{\mathrm{r}}\left(\overline{\overline{\mathrm{u}_{\mathrm{j}} \mathrm{u}_{\mathrm{s}} \varepsilon_{\mathrm{iks}}}}+\overline{\mathrm{u}_{\mathrm{i}} \mathrm{u}_{\mathrm{s}} \varepsilon_{\mathrm{jks}}}\right)
$$

20. pressure-strain term

$$
\phi_{i j}=p\left(\frac{\partial u_{i}}{\partial x_{j}}+\frac{\partial u_{j}}{\partial x_{i}}\right)
$$

21. decomposition of pressure-strain term

$$
\phi_{i j}=\phi_{i j, 1}+\phi_{i j, 2}+\phi_{i j}^{w}
$$

22. slow pressure-strain term

$$
\phi_{\mathrm{ij}, 1}=-\mathrm{C}_{1} \rho \frac{\varepsilon}{\mathrm{k}}\left[\overline{\mathrm{u}_{\mathrm{i}} \mathrm{u}_{\mathrm{j}}}-\frac{2}{3} \delta_{\mathrm{ij}} \mathrm{k}\right]
$$


23. rapid pressure-strain term

$$
\phi_{\mathrm{ij}, 2}=-\mathrm{C}_{2}\left[\begin{array}{l}
\left(\mathrm{P}_{\mathrm{ij}}+\mathrm{F}_{\mathrm{ij}}+\mathrm{B}_{\mathrm{ij}}+\frac{\partial}{\partial \mathrm{x}_{\mathrm{r}}}\left(\rho \mathrm{U}_{\mathrm{r}} \overline{\mathrm{u}_{\mathrm{i}} \mathrm{u}_{\mathrm{j}}}\right)\right) \\
+\frac{2}{3} \delta_{\mathrm{ij}}\left(\frac{1}{2} \mathrm{P}_{\mathrm{rr}}+\frac{1}{2} \mathrm{~B}_{\mathrm{rr}}-\frac{1}{2} \frac{\partial}{\partial \mathrm{x}_{\mathrm{r}}}\left(\rho \mathrm{U}_{\mathrm{r}} \overline{\mathrm{u}_{\mathrm{r}} \mathrm{u}_{\mathrm{r}}}\right)\right)
\end{array}\right]
$$

24. wall reflection term

$$
\begin{aligned}
& \phi_{i j}^{w}=C_{1}^{\prime} \frac{\varepsilon}{k}\left(\overline{u_{r} u_{s}} n_{r} n_{s} \delta_{i j}-\frac{3}{2} \overline{u_{i} u_{r}} n_{j} n_{r}-\frac{3}{2} \overline{u_{j} u_{r}} n_{i j} n_{r}\right) \frac{k^{3 / 2}}{\left(C_{\mu}^{3 / 4} / \kappa\right) \varepsilon d_{w}} \\
& \mathrm{C}_{2}^{\prime}\left(\phi_{\mathrm{rs}, 2} \mathrm{n}_{\mathrm{s}} \mathrm{n}_{\mathrm{s}} \delta_{\mathrm{ij}}-\frac{3}{2} \phi_{\mathrm{ir}, 2} \mathrm{n}_{\mathrm{j}} \mathrm{n}_{\mathrm{r}}-\frac{3}{2} \phi_{\mathrm{jr}, 2} \mathrm{n}_{\mathrm{i}} \mathrm{n}_{\mathrm{r}}\right) \frac{\mathrm{k}^{3 / 2}}{\left(\mathrm{C}_{\mu}^{3 / 4} / \kappa\right) \varepsilon \mathrm{d}_{\mathrm{w}}}
\end{aligned}
$$

\section{Nomenclature}

\section{General Symbols}

$\mathrm{C}=$ coefficient

$\mathrm{C}_{1}^{\prime}=$ constant in the linear pressure-strain model, for the wall reflection term $=0.5$

$\mathrm{C}_{2}^{\prime} \quad=$ constant in the linear pressure-strain model, for the wall reflection term $=0.3$

B = buoyancy effect term from Reynolds stress model

$\mathrm{d}_{\mathrm{w}} \quad=$ distance to the wall $(\mathrm{m})$

$\mathrm{d} \quad=$ particle diameter $(\mathrm{m})$

$\mathrm{F} \quad=$ external forces $\left(\mathrm{kg} \mathrm{m} \mathrm{s}^{-2}\right)$

$\mathrm{F} \quad=$ effect of system rotation of the Reynolds stress model

$\mathrm{f} \quad=$ dimensionless friction factor $(-)$ 
$\mathrm{G}=$ generation of turbulent energy $\left(\mathrm{kg} \mathrm{m}^{-1} \mathrm{~s}^{-3}\right)$

$\mathrm{g} \quad=$ acceleration due to gravity $\left(\mathrm{m} \mathrm{s}^{-2}\right)$

$\mathrm{k} \quad=$ kinetic energy $\left(\mathrm{m}^{2} \mathrm{~s}^{-2}\right)$

$\mathrm{n} \quad=$ unit normal vector (where the subscript defines the direction of the vector)

$\mathrm{p} \quad=$ pressure shared by all phases $\left(\mathrm{N} \mathrm{m}^{-2}\right)$

$\operatorname{Re} \quad=$ Reynolds number $(-)$

$\mathrm{t}=$ time $(\mathrm{s})$

$\mathrm{u} \quad=$ velocity component $\left(\mathrm{m} \mathrm{s}^{-1}\right)$

$\mathrm{V} \quad=$ slip velocity component $\left(\mathrm{m} \mathrm{s}^{-1}\right)$

$\mathrm{x} \quad=$ spatial co-ordinate $(\mathrm{m})$

\section{Greek Symbols}

$\beta \quad=$ coefficient of thermal expansion

$\varepsilon \quad=$ rate of dissipation of turbulent energy $\left(\mathrm{m}^{2} \mathrm{~s}^{-2}\right)$

$\phi \quad=$ pressure strain

$\kappa=$ constant for the linear pressure-strain model wall reflection term $=0.41$

$\mu \quad=\operatorname{viscosity}\left(\mathrm{kg} \mathrm{m}^{-1} \mathrm{~s}^{-1}\right)$

$\rho \quad=$ density $\left(\mathrm{kg} \mathrm{m}^{-3}\right)$

$\Omega \quad=$ mean rate of rotation tensor

$\sigma_{\mathrm{k}} \quad=$ turbulent Prandtl number for the kinetic energy $=1(\mathrm{k}-\varepsilon$ turbulence transport $)$ or 0.82

(Reynolds stress turbulence transport)

$\sigma_{\varepsilon} \quad=$ turbulent Prandtl number for the rate of dissipation of energy $=1.3$

\section{Mathematical Operators}

$\mathrm{D} \quad=$ total differential operator

$\mathrm{d} \quad=$ differential operator

$\partial \quad=$ partial differential operator 
$\wp=$ material derivative

$\rightarrow \quad=$ vector form of variable (i.e. representing $\mathrm{i}, \mathrm{j}$ and $\mathrm{k}$ forms of the variable as a matrix)

\section{Subscripts and Superscripts}

$1=$ constant for the linear pressure-strain model $=1.8$

$2=$ constant for the linear pressure-strain model $=0.6$

$1 \varepsilon \quad=$ constant for the turbulent dissipation of energy $=1.44$

$2 \varepsilon \quad=$ constant for the turbulent dissipation of energy $=1.92$

$3 \varepsilon \quad=$ constant for the turbulent dissipation of energy

$\mathrm{b} \quad$ = buoyancy

c $\quad=$ continuous phase

$\mathrm{D}_{\mathrm{p}} \quad=$ drift velocity of the pth phase

$\mathrm{i}=$ co-ordinate index

$\mathrm{j} \quad=$ co-ordinate index normal to $\mathrm{i}$

$\mathrm{k} \quad=$ kinetic energy

$\mathrm{m}=$ mixture phase index

$\mathrm{n} \quad=$ number of phases

$\mathrm{p} \quad=$ particle index

$\mathrm{q}=$ phase index

$\mathrm{r} \quad=$ co-ordinate index

$\mathrm{s}=$ co-ordinate index

$\mathrm{t}=$ turbulent

$\mathrm{w} \quad=$ wall effects

$\mu \quad=$ turbulent viscosity constant $=0.09$ 


\section{References}

1. Fluent Solvers, Fluent Europe Ltd, Sheffield Airport Business Park, Europa Link, Sheffield S9 1XU (www.fluent.co.uk)

2. Cartland Glover, G. M., Generalis, S. C., and Thomas, N. H., Chem. Pap. 54, 361 (2000)

3. Cartland Glover, G. M., Generalis, S. C., and Thomas, N. H., Chisa 2000, G5.5, Prague, Czech Republic, 27-31 August 2000

4. Chisti, M. Y. Airlift Bioreactors, Elsevier Science Publishers Ltd, New York, 1989

5. Klein, J., Dolgoš, O., Godó., Š., Blažej., M., and Markoš. J., Chem. Pap. 54, 456 (2000)

6. Manninen, M. Taivassalo V. and Kallio, S. On the mixture model for multiphase flow, VTT Publications: 288, Espoo, Finland 1996.

7. Sanyal, J., Vásquez, S., Roy, S. and Duduković M. P., Chem. Eng. Sci. 54, 5071 (1999).

8. Fluent Inc., Fluent 5 Users Guide, Lebanon, New Hampshire, USA 1998

9. Leonard, B. P., Comp. Meth. Appl. Mech. 19, 59 (1979).

10. Patanakar, S. V., Numerical Heat Transfer and Fluid Flow, McGraw-Hill, New York 1980.

11. Kuncová, G., and Zahradník, J., Chem. Eng. \& Processing 34, 25 (1995)

12. Zahradník, J., Fialová, M., Ruzicka, M., Drahos, J., Kastánek F., and Thomas, N., H., Chem. Eng. Sci. 52, 3811 (1997)

13. Zahradník, J., Kuncová G., and Fialová M., Chem. Eng. Sci. 54, 2401 (1999) 
14. Ruzicka, M., Drahos, J., Zahradník, J., and Thomas, N., H., Chem. Eng. Sci. 55, 421 (2000) 